\title{
Beryllium window and acoustic delay line design for $x$-ray lithography beam lines at the University of Wisconsin Center for X-ray Lithography
}

\author{
E. L. Brodsky \\ Center for X-ray Lithography, University of Wisconsin, 3731 Schneider Drive, Stoughton, \\ Wisconsin 53589 \\ W. Hamilton \\ Nuclear Engineering and Engineering Physics, University of Wisconsin, 153 Engineering Research \\ Building, Madison, Wisconsin 53705 \\ G. Wells and F. Cerrina \\ Center for X-ray Lithography, University of Wisconsin, 3731 Schneider Drive, Stoughton, \\ Wisconsin 53589 \\ M. Corradini \\ Nuclear Engineering and Engineering Physics, University of Wisconsin, 153 Engineering Research \\ Building, Madison, Wisconsin 53705
}

(Presented on 16 July 1991)

$\mathrm{X}$-ray lithography systems require sample chambers that can perform exposures in helium gas at atmospheric pressure. The interface between the experimental chamber and the beamline is critical for $\mathrm{x}$-ray lithography and the storage ring. It must allow a high $\mathrm{x}$-ray flux throughput while providing a vacuum barrier so that helium gas does not leak into the beam line and the storage ring. The beam line must also be designed to have protection in the case that a window does fail in order to minimize adverse effects to the ring and other systems. The details of the design for the vacuum system used on beam lines for the Center for X-ray Lithography at the University of Wisconsin Synchrotron Radiation Center $1-\mathrm{GeV}$ electron storage ring are reported. Curved beryllium windows with a $1 \times 5-\mathrm{cm}^{2}$ aperture and $13 \mu \mathrm{m}$ thick that have a leak rate less than $10^{-10}$ Torr $\ell / \mathrm{s}$ have been successfully used at the experimental chamber beam-line interface. This thin flat beryllium foil is mounted in a curved housing with a wire seal to minimize helium leakage. The window assembly is designed and has been tested to withstand substantial overpressure before failure. If the beryllium window does fail, the beamline has an acoustic delay line that is designed to delay the incoming shock wave of helium gas so that a fast valve at the end of the beam line will close and minimize leakage of helium into the storage ring. The acoustic delay line is designed with baffles to slow the shock front and a secondary thin window to protect against molecular diffusion into the storage ring. The acoustic delay line has been tested to determine the effect of baffle design on delay of the shock wave. A theoretical model that provides a good description of the acoustic delay has also been developed.

\section{INTRODUCTION}

At the University of Wisconsin Center for X-ray Lithography (CXrL), $\mathrm{x}$-ray lithography beam lines interface the Synchrotron Radiation Center (SRC) Aladdin 1-GeV electron storage ring to lithography aligners, experimental chambers, and $\mathrm{x}$-ray steppers. A typical CXrL beam line is the Experimental Station 3 beam line (ES-3) that is near completion on bending magnet 11 at SRC. This beam line incorporates grazing incident optics to focus the synchrotron light into a tightly collimated horizontal image for use with an $\mathrm{x}$-ray stepper. A thin beryllium window at the end of the beam line serves as an interface between the ultrahigh vacuum (uhv) beam line and the $x$-ray lithography exposure chamber. At CXrL current lithography exposure chambers and other lithography tools are designed to be used in a helium environment at atmospheric pressure. To transmit the highest flux above the cutorf, the window is as thin as possible. The window must also safely support a pressure load of $1 \mathrm{~atm}$. Unlike many monochromator beam lines in use at Aladdin, the CXrL lithography beam lines lack small slits or other apertures that limit the beam-line vacuum conductance. If a beryllium window failed by breaking during operation, a helium pressure wave would travel down the beam line at a supersonic velocity to the storage ring. Due to the serious consequence of a vacuum accident to the storage ring, the lithography beam line, and the large number of users on the storage ring, many design features are incorporated in all CXrL lithography beam lines for vacuum protection. Using these design features, it is possible to reduce the chance of a beryllium window breakage having an impact on the storage ring. These unique design features include special beryllium window design, fast vacuum valves, acoustic delay lines, and a secondary window.

\section{BERYLLIUM WINDOWS}

The beryllium foil currently used by $\mathrm{CXrL}$ is $7.1 \times 9.9$ $\mathrm{cm}^{2}$ in size and $13 \mu \mathrm{m}$ thick and is manufactured by Brush 


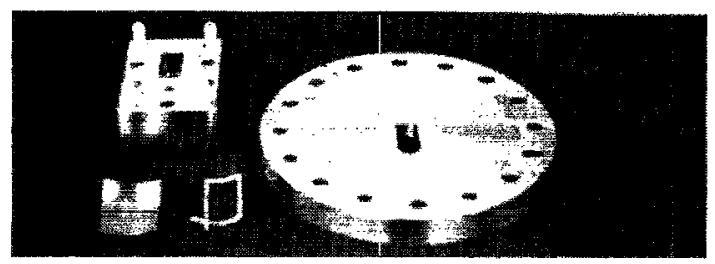

FIG. 1. Picture of a curved beryllium window assembly.

Wellman, Inc., Elmore, Ohio from rolled stock. The foils are selected to have a helium leak rate less than $10^{-10}$ Torr $\mathrm{l} / \mathrm{s}$. The beryllium foil is mounted in a vacuum flange and the foil has a cylindrical geometry when mounted. Figure 1 shows the beryllium foil and other components used in this mounting arrangement. The cylindrical geometry has been used successfully at CXrL for more than 1 year and other curved geometry windows have been reported by others. ${ }^{2}$ The current flange design has a $1 \times 5-\mathrm{cm}^{2} \mathrm{x}$-ray window area; Fig. 1 shows a small window assembly with a $1 \times 2.5-\mathrm{cm}^{2}$ window area. The use of a cylindrical geometry places the foil in tension under load and greatly improves the windows' load bearing capacity. Using the Hoop stress equation ${ }^{3}$ an estimate of the maximum allowable pressure can be calculated. If $d$ is the internal diameter, $t$ the foil thickness, and $s_{t}$ the ultimate tangential stress, then the maximum pressure in a cylindrical tube the equivalent size to the cross section of the window is

$$
p=2 t S_{t} / d
$$

Using a tube radius of $3.8 \mathrm{~cm}$ and the minimum ultimate tensile strength for beryllium of $4.83 \times 10^{8} \mathrm{~Pa}$ the estimate of the window burst pressure for a $25-\mu \mathrm{m}$ foil is $641 \times 10^{3}$ $\mathrm{Pa}$. A special test fixture was constructed to burst test a foil mount in this cylindrical geometry. A $25-\mu \mathrm{m}$-thick beryllium foil was tested and the foil failed at $827 \times 10^{3} \mathrm{~Pa}$. At CXrL the environment used in the exposure station is helium, which will cool the beryllium window and reduce any beryllium heat load problems. The presence of oxygen is monitored downstream of the beryllium window to insure that no oxygen is present. Any oxygen contamination on the high-pressure side of the window would cause production of ozone from the source $x$ tays that could etch the beryllium foil. The foil is sealed to the mounting flange with a thin aluminum wire. This method of mounting is preferred because it is an all-metal design that is useful for high-temperature bakeout. Before installation the complete assembly is tested to have a helium leak rate less than $10^{-10}$ Torr $1 / \mathrm{s}$. The windows have performed satisfactorily although it was observed that the relative large grain size (due to the rolling) would in some cases be visible in the exposures, particularly at low doses. This is not a real problem since the resist is normally overexposed in order to improve image definition and further processing. The graininess disappears completely for normal exposures, i.e., above the resist nominal sensitivity.

\section{FAST VALVES}

Due to the possibility of a beryllium window failure, a fast valve manufactured by VAT, Haag, Switzerland is incorporated into all $\mathrm{CXrL}$ beam lines. The valve is located near the storage ring. The location of the valve near the storage ring maximizes the time for the molecular flow and helium pressure wave to reach the fast valve. Should a vacuum failure occur at the bcryllium window end of the beam line this placement will minimize the amount of gas entering the storage ring through the valve before it closes. Either O-ring-sealed fast valves or fast shutters are used on the beam lines. The closing times for the valves range from 7 to $15 \mathrm{~ms}$ depending on the size and model of the valve. The valve is actuated by a cold cathode gauge located near the beryllium window assembly. The complete fast closing system with a controller is purchased from VAT. The system is set to trigger the valve to close within $1 \mathrm{~ms}$ after a pressure trip point is reached. Due to the high molecular velocity of helium and the high volumetric rate of gas inrush if a catastrophic window failure occurred, the fast valve along would not close before having a helium pressure rise into the storage ring. To delay the helium gas inrush an acoustic delay line and secondary window are also incorporated into the beam lines.

\section{SECONDARY WINDOW}

The secondary window on the CXrL beam line is either a $1-\mu \mathrm{m}$-thick SiN or Si vacuum leak tight window. Other materials can be used for this window with the primary selection factors being low $x$-ray absorption, resistance to $x$-ray damage, and high mechanical strength. This secondary window will also serve as a barrier to helium leakage into the storage ring if a small leak in the beryllium window would develop. The vacuum system is designed with a vacuum bypass around the secondary window to allow for vacuum pumpdown. For a catastrophic beryllium window failure, the secondary window will stop gas flow into the storage ring until this secondary window pressurizes and the window bursts. The secondary windows on CXrL beam lines are designed to safely withstand a pressure rise of 50 Torr. This feature enhances the performance of the acoustic delay line.

\section{ACOUSTIC DELAY LINE}

Acoustic delay lines have been used on various storage rings. ${ }^{4}$ The basic approach is that of trying to slow down the incoming shock waves by placing various apertures along the expansion path. Commercial delay lines are also available from Vacuum Generators Limited, East Sussex, U.K. We have developed a thcoretical model of the gas expansion in an evacuated container and applied the results to the design of our delay lines. The CXrL ES-3 beam line is designed with a scanning mirror and moving beryllium window assembly that can accommodate a full $50 \times 50-\mathrm{mm}^{2}$ image field. Due to concerns about the large beam-line piping and the acoustic delay line, a complete experimental program was initiated to test for the optimum design. A sketch of the test assembly is shown in Fig. 2. A 


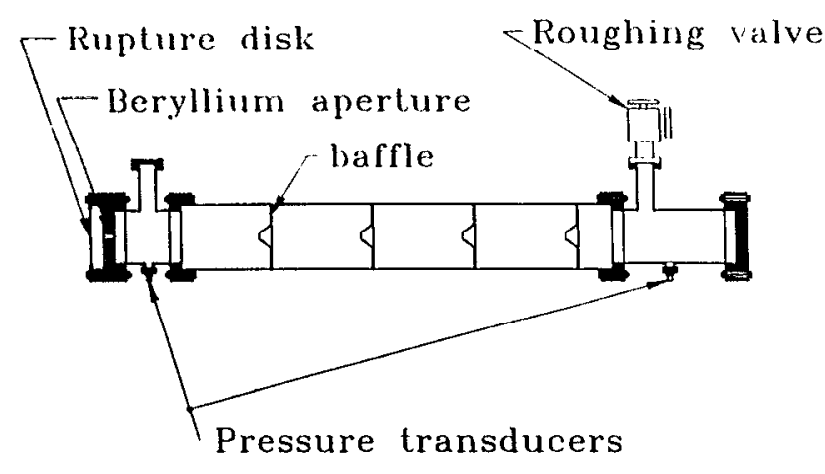

FIG. 2. Sketch of experimental acoustic delay line.

1-m-long 15.25-cm-diam delay line was constructed that allowed a variable number of apertures to be installed for this experiment. The apertures had an open area of $1 \times 5$ $\mathrm{cm}^{2}$. The delay line was implemented with two piezoelectric pressure transducers. The transducers are manufactured by PCB, Inc. model number $106 \mathrm{~B}$ with a $5-\mu$ s risetime constant. A rupture disk was installed upstream of the beryllium window aperture. This disk allowed for a uniform test chamber pressurization. The test chamber was pumped down to less than $10^{-6}$ Torr and the rupture disk was broken with a pneumatically actuated knife. The pressure rise at the transducers in the chamber was measured using a digital oscilloscope. A computer program was written to simulate the failure of a window considering the baffles as a series of separated chambers. From a theoretical point of view, the flow can be modeled as an expansion of gas in a series of interconnected chambers of various volumes. After the rupture of the beryllium window, the gas moves successively from chamber to chamber until it reaches the silicon window. Initially the pressure differential is large, and it can be shown that the gas flow is only a function of the upstream pressure. ${ }^{5}$ The flow rates can be calculated using the choked flow equation. ${ }^{5}$ In this case $m$ is the mass flow rate, $p_{0}$ is the upstream pressure, $A$ is the aperture area, $T$ is the temperature, $c_{p}$ is the isobaric specific heat capacity, and $\gamma$ is the ratio of specific heats,

$$
\dot{m}=\frac{A p_{0}}{\sqrt{c_{p} T}} \frac{\gamma}{\sqrt{\gamma-1}}\left(\frac{\gamma+1}{2}\right)^{(-1 / 2)(\gamma+1 / \gamma-1)} .
$$

As the differential pressure between adjacent chambers decreases, the flow will no longer be choked flow. It is then governed by the isentropic flow relationship ${ }^{5}$ and the mass flow is dependent on the gas velocity through the aperture,

$$
\dot{m}=\frac{A p_{0}}{\sqrt{c_{p} T}} \frac{\gamma}{\sqrt{\gamma-1}} M\left(1+\frac{\gamma+1}{2} M^{2}\right)^{(-1 / 2)(\gamma+1 / \gamma-1)} .
$$

The Mach number $M$ is calculated as the ratio of gas velocity and the speed of sound in the gas. Calculating the mass flow on a time basis, the total mass $m$ into each subchamber can be calculated. Using the gas law the pressure in the last chamber before the secondary window can be calculated as

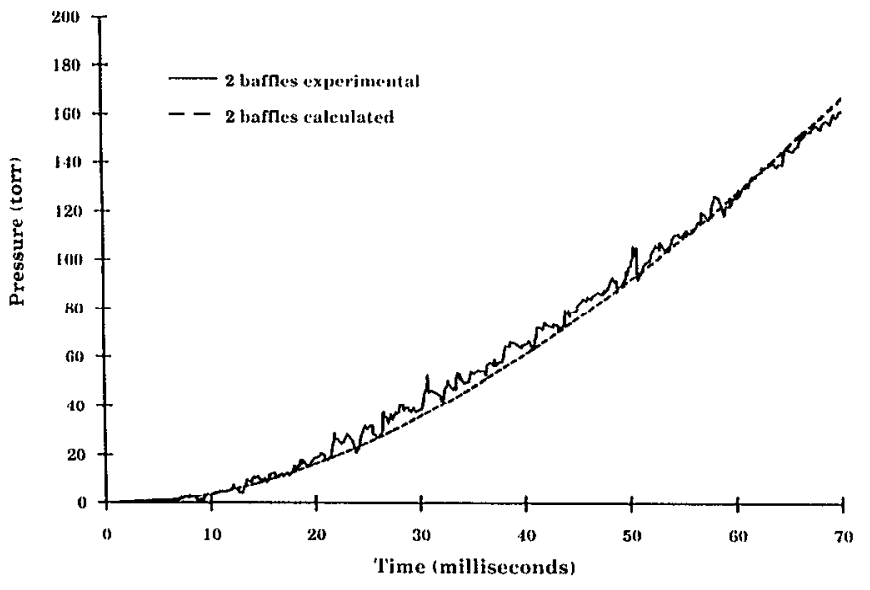

FIG. 3. Comparison of calculated vs experimental pressure rise for two baffles.

$$
P_{f}=\frac{m_{f}}{V_{f}} R T,
$$

with $P_{f}, m_{f}$ and $V_{f}$ being the pressure, mass, and volume in the subchamber.

The time for the end chamber pressure to rise to 50 Torr in the chamber was then compared to calculated values. Over the range of $70 \mathrm{~ms}$ the measured and calculated values show good agreement for $0-4$ baffles. Figures 3 and 4 show the comparison for a delay line with two and four baffles and air as the gas. Although the experiments were performed in air, the results can be extrapolated to helium. It is possible to estimate the difference in pressure rise in a subchamber filling with air or helium through a fixed aperture using the choked flow equation. Using the constants below, the pressure in the chamber would rise 2.8 times faster if filled with helium than if filled with air.

\begin{tabular}{lrc} 
& Air & Helium \\
\cline { 2 - 3 }$C_{p}\left(\mathrm{~J} / \mathrm{kg}^{\circ} \mathrm{C}\right)$ & 1006 & 5188.6 \\
$\gamma$ & 1.4 & 1.66
\end{tabular}

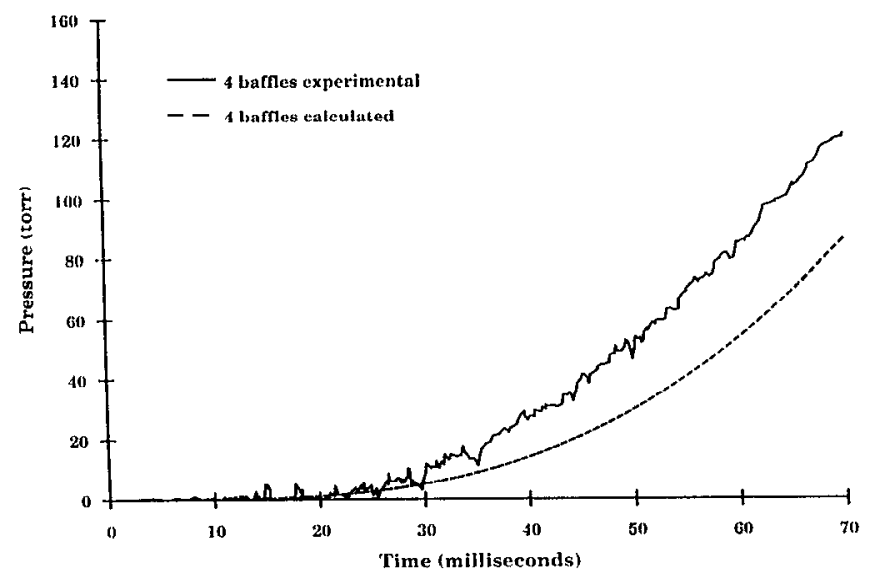

FIG. 4. Comparison of calculated vs experimental pressure rise for four baffles. 
One important factor that leads to an increase in the time delay in this design is the addition of a large volume between the last baffle and the secondary window. The larger the volume, the larger the time delay in pressurizing the volume to 50 Torr. Another concern is the possibility of a large forward-directed pressure wave that could flow though each baffle and rupture the Si or SiN window. Several tests were done with the piezoelectric pressure transducer on axis at the end of the delay line. Although there are small oscillations due to shock waves and resonances in the baffles, the peak intensity measured on the transducer was less than 50 Torr. Although a complete test on a beam line has not been performed the experiment results are encouraging in their support of protection against a catastrophic beryllium window. It is important to notice that it is possible to use the model developed to design a system of baffles that will minimize the pressure rise at the ring, thus providing a very effective protection for the ring operation.

\section{CONCLUSION}

An alternative to and improved design for implementing a system to protect a storage ring in the event of a catastrophic failure of a beryllium window has been experimentally tested. This design incorporates a secondary 1$\mu \mathrm{m}$ window in the beam line. The secondary window has been designed to withstand a pressure of 50 Torr. Using the secondary window as part of the acoustic delay line it is possible in the case of a beryllium window failure to slow the inrush of helium and allow the final fast valve to close before helium will leak into the storage ring. The number of baffles and the volumes required for each of the subchambers can be modeled using the isentropic and choked gas flow equations. By the use of this model the volumes can be adjusted for CXrL beam lines to have $30 \mathrm{~ms}$ or more of time before the secondary window will fail; this will allow a factor of safety for the 15 -ms fast valve to completely close. The addition of a curved beryllium window substantially improves the load bearing capacity of the window, and based on this design, $13-\mu \mathrm{m}$ beryllium windows have been successfully used at CXrL.

\section{ACKNOWLEDGMENT}

This work is supported by DARPA.

${ }^{1}$ H. Betz, P. Hof bauer, and A. Heuberger, J. Vac. Sci. Technol. 16, 924 (1979).

${ }^{2}$ R. Rippstein, IBM Tech. Discl. Bull. 33, 190 (1990).

${ }^{3}$ J. E. Shigley and L. D. Mitchell, Mechanical Engineering Design, 4 th ed. (McGraw-Hill, New York, 1983).

${ }^{4}$ W. Peatman and E. W. Weiner, J. Vac. Sci. Technol. 17, 1237 (1980).

${ }^{5} \mathrm{D}$. Daneshyar, One-Dimensional Compressible Flow (Pergamon, New York 1976). 